\title{
CORRECTION
}

\section{Correction: Association of symptoms and interval breast cancers in the mammography-screening programme: population-based matched cohort study}

Deependra Singh ${ }^{1,2}$, Joonas Miettinen ${ }^{1}$, Stephen Duffy $^{3}$, Nea Malila ${ }^{1,2}$, Janne Pitkäniemi ${ }^{1}$ and Ahti Anttila ${ }^{1}$

British Journal of Cancer (2019) 120:773-774; https://doi.org/10.1038/s41416-019-0417-6

Correction to: British Journal of Cancer (2018) 119, 1428-1435; https://doi.org/10.1038/s41416-018-0308-2; www.bjcancer.com; published online 7 November 2018.

The authors report that the labels indicating the symptom types and no symptom lines in the original version of Fig. 2 were missing. The correct version of Fig. 2 with the labels included is provided below.

\begin{abstract}
Open Access This article is licensed under a Creative Commons Attribution 4.0 International License, which permits use, sharing, adaptation, distribution and reproduction in any medium or format, as long as you give appropriate credit to the original author(s) and the source, provide a link to the Creative Commons license, and indicate if changes were made. The images or other third party material in this article are included in the article's Creative Commons license, unless indicated otherwise in a credit line to the material. If material is not included in the article's Creative Commons license and your intended use is not permitted by statutory regulation or exceeds the permitted use, you will need to obtain permission directly from the copyright holder. To view a copy of this license, visit http://creativecommons. org/licenses/by/4.0/.
\end{abstract}

(c) The Author(s) 2019

\footnotetext{
${ }^{1}$ Mass Screening Registry, Finnish Cancer Registry, Fl-00130 Helsinki, Finland; ${ }^{2}$ Epidemiology group, Department of Health Sciences, University of Tampere, Fl-33520 Tampere, Finland and ${ }^{3}$ Wolfson Institute of Preventive Medicine, Queen Mary University of London, Charterhouse Square, London, England Correspondence: Deependra Singh (deependra.singh@cancer.fi)
}

Published online: 6 March 2019 

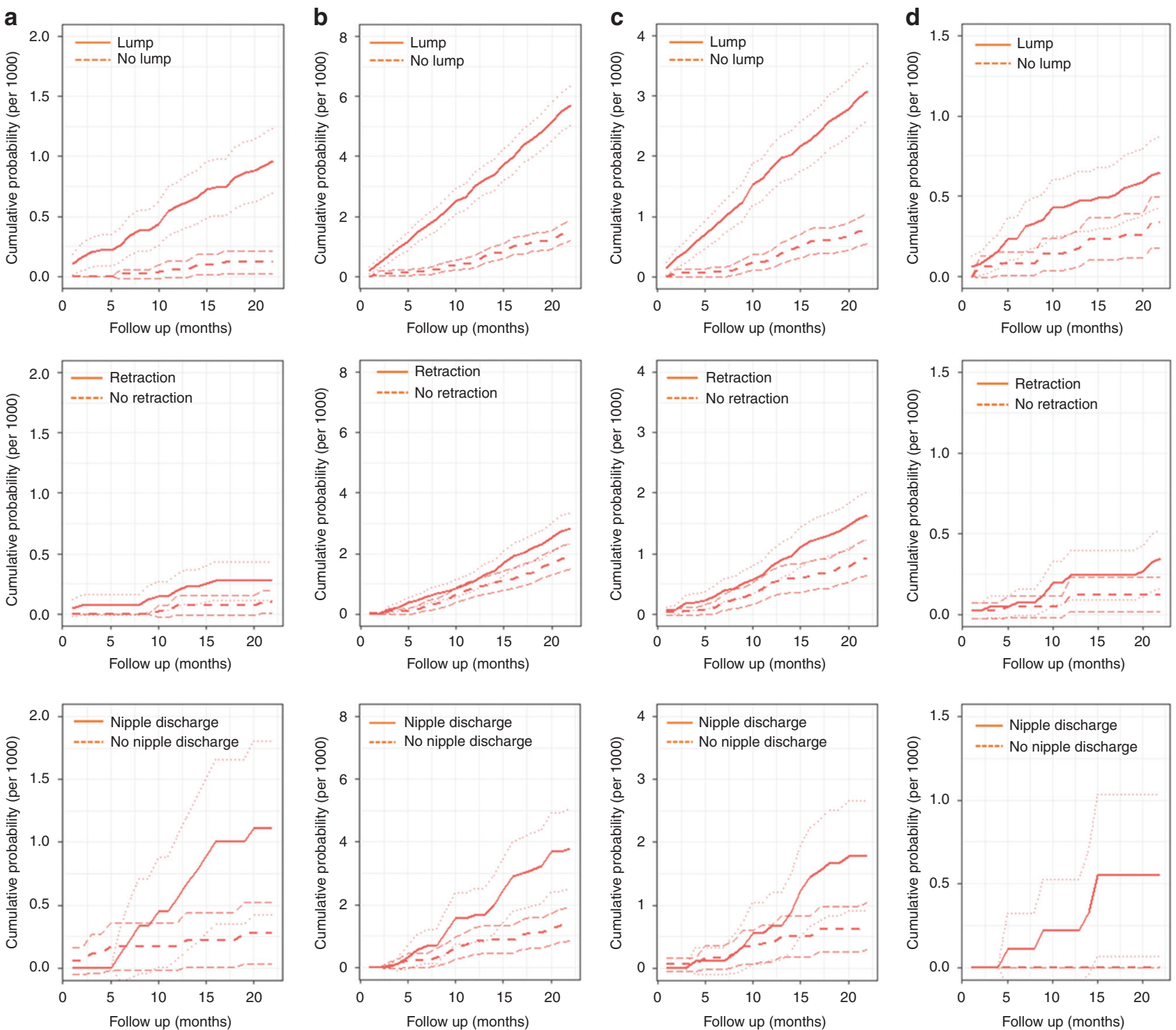

Fig. 2 a-d Cumulative incidence of invasive (per 1000): a recalled ICs; b not recalled ICs; c non-localised ICs; d fatal interval cancers. Note: the confidence intervals lines for cumulative incidence are indicated by light dotted lines in symptomatic and asymptomatic groups 